\title{
OS MÉDICOS, A SAÚDE COMO COMPLETO BEM-ESTAR E A QUESTÃO DO DESENVOLVIMENTO
}

Roberto P. Nogueira

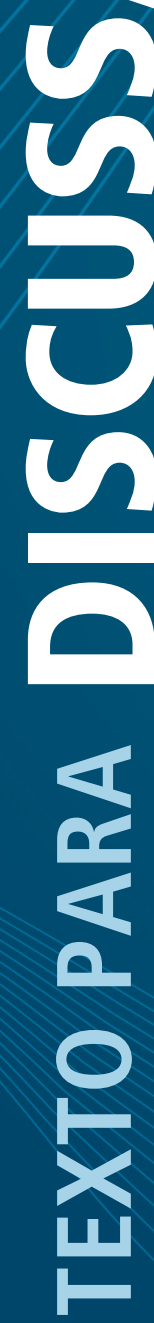





\section{TEXTO PARA DISCUSSÃO}

Brasília, setembro de 2020

\section{OS MÉDICOS, A SAÚDE COMO COMPLETO BEM-ESTAR E A QUESTÃO DO DESENVOLVIMENTO ${ }^{1}$}

Roberto P. Nogueira

1. Especiais agradecimentos aos colegas da Diretoria de Estudos e Políticas do Estado (Diest) do Ipea, Mauricio Saboya Pinheiro, pela acurada revisão do texto e sugestões, e Luis Carlos Magalhães, pelas sugestões e incentivo.

2. Médico e técnico de planejamento e pesquisa na Diest//pea.E-mail: <roberto.nogueira@ipea.gov.br>. 


\section{Governo Federal}

Ministério da Economia

Ministro Paulo Guedes

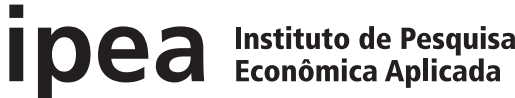

Fundação pública vinculada ao Ministério da Economia, o Ipea fornece suporte técnico e institucional às ações governamentais - possibilitando a formulação de inúmeras políticas públicas e programas de desenvolvimento brasileiros - e disponibiliza, para a sociedade, pesquisas e estudos realizados por seus técnicos.

Presidente

Carlos von Doellinger

Diretor de Desenvolvimento Institucional

Manoel Rodrigues Junior

Diretora de Estudos e Políticas do Estado, das Instituições e da Democracia

Flávia de Holanda Schmidt

Diretor de Estudos e Políticas

Macroeconômicas

José Ronaldo de Castro Souza Júnior

Diretor de Estudos e Políticas Regionais,

Urbanas e Ambientais

Nilo Luiz Saccaro Júnior

Diretor de Estudos e Políticas Setoriais de Inovação e Infraestrutura

André Tortato Rauen

Diretora de Estudos e Políticas Sociais

Lenita Maria Turchi

Diretor de Estudos e Relações Econômicas e

Políticas Internacionais

Ivan Tiago Machado Oliveira

\footnotetext{
Assessora-chefe de Imprensa e

Comunicação

Mylena Fiori

Ouvidoria: http://www.ipea.gov.br/ouvidoria

URL: http://www.ipea.gov.br
}

\section{Texto para Discussão}

Publicação seriada que divulga resultados de estudos e pesquisas em desenvolvimento pelo Ipea com o objetivo de fomentar o debate e oferecer subsídios à formulação e avaliação de políticas públicas.

(C) Instituto de Pesquisa Econômica Aplicada - ipea 2020

Texto para discussão / Instituto de Pesquisa Econômica Aplicada.- Brasília : Rio de Janeiro : Ipea, 1990-

ISSN 1415-4765

1.Brasil. 2.Aspectos Econômicos. 3.Aspectos Sociais. I. Instituto de Pesquisa Econômica Aplicada.

CDD 330.908

As publicações do Ipea estão disponíveis para download gratuito nos formatos PDF (todas) e EPUB (livros e periódicos). Acesse: http://www.ipea.gov.br/portal/publicacoes

As opiniões emitidas nesta publicação são de exclusiva e inteira responsabilidade dos autores, não exprimindo, necessariamente, o ponto de vista do Instituto de Pesquisa Econômica Aplicada ou do Ministério da Economia.

É permitida a reprodução deste texto e dos dados nele contidos, desde que citada a fonte. Reproduções para fins comerciais são proibidas. 


\section{SUMÁRIO}

SINOPSE

1 INTRODUÇÃO

7

2 A MEDICINA SOCIAL EUROPEIA E AS ORIGENS UTILITARISTAS DA DEFINIÇÃO DE SAÚDE DA OMS. 9

3 AS CRIITICAS À DEFINIÇÃO DE SAÚDE DA OMS

4 UMA HIPÉRBOLE DESENVOLVIMENTISTA PRECOCE.

5 MYRDAL: O BEM-ESTAR, OS ASPECTOS ECONÔMICOS DA SAÚDE E A IDEIA DE REFORMA SANITÁRIA. 15

6 MEDICINA, ECONOMIA E DESENVOLVIMENTO NO BRASIL 17

7 O BEM-ESTAR DE ONTEM E DE HOJE 20

8 OUTRAS CONCEPÇÕES DA SAÚDE HUMANA PARA ALÉM DO BEM-ESTAR 21

9 À GUISA DE CONCLUSÃO 28

REFERÊNCIAS 29

BIBLIOGRAFIA COMPLEMENTAR 30 



\section{SINOPSE}

Este estudo procura evidenciar que a conhecida definição de saúde como um completo bem-estar, conforme consta dos estatutos da Organizaçáo Mundial de Saúde (OMS), definidos em 1946, surgiu da influência da doutrina utilitarista de Jeremy Bentham sobre alguns médicos europeus propugnadores da medicina social. Considera-se que a ideia de completo bem-estar deve também ser interpretada prospectivamente pela questáo econômico-social do desenvolvimento, conforme seria ratificado em 1952 mediante as ideias desenvolvimentistas do economista sueco Gunnar Myrdal. Neste trabalho, são expostas brevemente as ideias desenvolvimentistas de dois médicos brasileiros, seguidores de Myrdal, Josué de Castro e Mário Magalhães da Silveira. Ademais, o texto defende a tese de que a difusão dos estudos acerca da transição epidemiológica a partir da década de 1970 fez com que médicos pesquisadores de diferentes partes do mundo viessem a renovar seu interesse pela questão do desenvolvimento, especialmente em relação à prioridade das doenças tropicais negligenciadas, entendidas como uma falência da promessa de saúde como completo bem-estar. Adicionalmente, o texto enfoca as ideias de cunho humanista de Amartya Sen sobre saúde como liberdade, e a concepção fenomenológica de Martin Heidegger sobre saúde como estar bem.

Palavras-chave: saúde e bem-estar; saúde e desenvolvimento; saúde e liberdade. 



\section{INTRODUÇÃO}

Os estatutos da Organização Mundial da Saúde (OMS) foram aprovados em conferência internacional realizada na cidade de Nova Iorque, em julho de 1946, menos de um ano após o término da Segunda Guerra Mundial. A definição de saúde incorporada a esses estatutos é bem conhecida: "saúde é o estado de completo bem-estar físico, mental e social e não meramente a ausência de doença ou enfermidade" (WHO, 1946b).

Neste estudo, procuramos evidenciar que essa definição decorreu da influência da doutrina utilitarista de Jeremy Bentham sobre alguns médicos europeus propugnadores da medicina social. Contudo, consideramos que a ideia de completo bem-estar deve ser interpretada não apenas de acordo com essa inspiração filosófica, mas também considerando os objetivos estratégicos da OMS na conjuntura especial do pós-guerra, marcada pelo desafio da reorganização econômico-social dos países (post-war reconstruction) e, prospectivamente, pela questão do desenvolvimento.

Entendemos que o conceito de saúde como completo bem-estar constitui uma hipérbole desenvolvimentista precoce. Isto quer dizer que, mediante um exagero retórico, ou seja, uma hipérbole, a noção de completo bem-estar apontava para o resultado esperado do processo de desenvolvimento econômico-social no pós-guerra. Em 1946, essa definição ainda exibia bases relativamente precárias, na medida em que se apoiava apenas no utilitarismo de Jeremy Bentham e no entusiasmo de um grupo pequeno de adeptos da medicina social. Contudo, em 1952, seria grandemente fortalecida mediante as ideias do economista sueco Gunnar Myrdal, expostas na própria sede da OMS. Além de economista renomado internacionalmente, Myrdal então presidia o Conselho Econômico e Social da Organização das Nações Unidas (ONU).

No Brasil, dois médicos admiradores de Myrdal costumam ser lembrados quando se discute a relação entre saúde e desenvolvimento: Josué de Castro e Mário Magalhães da Silveira. Naturais da região nordestina, ambos elaboraram seus estudos iniciais a partir de dados e métodos peculiares à demografia médica e à epidemiologia e centraram suas análises nos efeitos das desigualdades sociais sobre as condições de saúde e bem-estar da população. Esses e outros médicos brasileiros empenharam-se em provar diante das autoridades nacionais, mediante dados apropriados, que as más condições de saúde decorriam da desnutrição, da mortalidade infantil e da reduzida expectativa geral de vida da população, trazendo implicaçóes negativas para o desempenho da economia brasileira. 
Vários indicadores demográficos e epidemiológicos eram usados por esses e outros médicos brasileiros dessa época com o propósito de evidenciar o valor econômico da saúde. Este é o título de um alentado documento, escrito em inglês, de autoria dos médicos sanitaristas Paulo de Assis Ribeiro, Manoel José Ferreira e Ernani Braga, da Escola de Saúde Pública de Manguinhos (atual Fundação Oswaldo Cruz - Fiocruz), apresentado na mencionada conferência internacional da OMS de 1952. Esse tipo de abordagem quantitativa da relação entre saúde e desenvolvimento remonta aos métodos originalmente concebidos pelo economista e matemático alemão Wilhelm Lexis (1837-1914) e busca mensurar as tendências de natalidade, morbidade e mortalidade dos diferentes estratos populacionais e suas consequências para a sociedade.

A linha de estudos médicos acerca do valor econômico da saúde viria a alcançar grande repercussão internacional no início da década de 1970 por meio da teoria da transição epidemiológica, concebida pelo médico de origem egípcia Abdel Omram, professor de saúde pública nos Estados Unidos. Segundo Omram (2005), as mudanças demográficas e epidemiológicas devem ser entendidas como constituindo, simultaneamente, determinantes e consequências do desenvolvimento de cada país. Nesse sentido, os programas de controle ou de erradicaçáo de doenças transmissíveis nos países do chamado terceiro-mundo podem constituir em si mesmos um instrumento de desenvolvimento socioeconômico e não apenas um pré-requisito para alcançar padróes mais baixos de natalidade da população, objetivo que, por longo tempo, foi a preocupação predominante entre as agências de cooperação internacional financiadas pelo governo americano.

A difusão dos estudos acerca da transição epidemiológica fez com que médicos pesquisadores de diferentes partes do mundo viessem a renovar seu interesse pela questão do desenvolvimento. Em décadas recentes, essa linha de estudos direcionou seu foco de prioridade para a pesquisa sobre as assim denominadas doenças tropicais negligenciadas, um grupo amplo que inclui a malária, a dengue e a hanseníase, entre outras. Trata-se de doenças que, caracteristicamente, afetam os estratos paupérrimos e socialmente marginalizados da população, nos rincôes insulados do território brasileiro e de muitos outros países da África, da Ásia e da América Latina, onde não chegou ainda o tão prometido desenvolvimento econômico-social, com seu pressuposto bem-estar.

Tendo em mente esses e muitos outros exemplos de aplicação de métodos demográficos e epidemiológicos, que obtiveram e ainda obtêm ampla repercussão no campo da saúde pública, defendemos aqui a interpretaçáo de que, de modo geral, os médicos 
de carreira acadêmica não se sentem à vontade diante de interpretaçôes puramente teóricas da relação entre saúde e desenvolvimento. É o caso da concepçáo humanista de Amartya Sen sobre saúde como liberdade, e, de certo modo, a concepção fenomenológica de Martin Heidegger sobre saúde como estar bem, embora esta última seja estritamente filosófica e não se relacione com as perspectivas do desenvolvimento. Não obstante, optamos por incluir neste texto uma breve resenha dessas duas abordagens, na medida em que seus autores trouxeram contribuiçôes explicitamente contrapostas à noção de saúde como bem-estar e, de modo amplo, contrapostas às correntes utilitaristas, tanto no âmbito da filosofia quanto da economia.

Além desta introdução, a seção 2 aborda a medicina social europeia e a definição da saúde como completo bem-estar. $\mathrm{Na}$ seçáo 3, realizam-se críticas dirigidas a essa definição. A seção 4 apresenta a definição da OMS entendida como uma hipérbole desenvolvimentista precoce. $\mathrm{Na}$ seção 5 , são explicitados os aspectos econômicos da saúde e a ideia de reforma sanitária de Myrdal. Na seção 6, são apresentados os médicos brasileiros, a economia e o desenvolvimento. A seção 7 expóe o bem-estar de ontem e hoje. A seção 8 aponta um contraponto conceitual à concepção de bem-estar na tradição utilitarista, abordando brevemente duas questóes: $i)$ a saúde como estar bem segundo Heidegger; e ii) as capacidades humanas segundo Amartya Sen e o contexto epidemiológico das doenças crônicas não transmissíveis. Por fim, na seção 9, é feita uma conclusão geral.

\section{A MEDICINA SOCIAL EUROPEIA E AS ORIGENS UTILITARISTAS DA DEFINIÇÃO DE SAÚDE DA OMS}

Da comissão preparatória para a definição dos estatutos da OMS, que se reuniu em março de 1946, em Paris, participaram três das mais importantes figuras da medicina social europeia dessa época: o belga René Sand, o croata Andrija Stampar e o norueguês Karl Evang (WHO, 1946b). O Brasil esteve representado pelo médico Geraldo de Paula Souza, fundador da Escola de Saúde Pública da Universidade de São Paulo (USP).

René Sand, que exerceu a função de coordenador e relator da comissão, era o mais conhecido de todos em virtude de sua expressiva atuação em assessorias internacionais acerca da teoria e prática da medicina social. Sand era também a principal liderança europeia no campo das políticas de serviço social, ainda incipientes nessa época. De sua 
parte, Stampar viria a se destacar como presidente da I Conferência Internacional de Saúde da OMS em 1948. Ambos tinham em comum o sentimento de frustração com os objetivos e métodos da medicina realizada em consultórios particulares, a que denominavam de "medicina individual prática”, e lamentavam o desaparecimento do espírito social entre os médicos. Consideravam que o avanço para a medicina social seria inevitável porque o cuidado médico meramente individual encontrava-se em franca crise.

São diversas as indicaçóes de que a fonte original de inspiração para a ideia de saúde como completo bem-estar foi o utilitarismo de Jeremy Bentham, com sua compreensão "fisiológica" da saúde como um modo de prazer, em contraposição ao desprazer peculiar às enfermidades, conforme referido em sua obra clássica Uma introdução aos princípios da moral e da legislação, de $1781 .^{1}$

No capítulo V, Bentham (2000, p. 36) afirma que o prazer da saúde "é o sentimento ou fluxo interno agradável das sensaçóes que acompanha um estado de plena saúde e vigor, especialmente em momentos de esforço corporal moderado". A seguir, acrescenta: "pode-se dizer que um homem está em estado de saúde quando não tem sensaçóes desagradáveis que possam ser percebidas em qualquer lugar do seu corpo”. Essa concepção individualista e organicista entende que o bem-estar específico da saúde e o bem-estar social de modo geral são constituídos pelo somatório das utilidades individuais positivas e negativas, ou seja, do prazer e do desprazer em seus fundamentos fisiológicos e sensoriais.

As ideias de Bentham foram muito apreciadas pelos autores da medicina social europeia da década de 1930. Sob a liderança de René Sand, esses médicos cultivaram a noção de bem-estar como um dos temas fundamentais de pesquisa e de ensino acadêmico. Em seu livro L'Économie Humaine par la Médicine Sociale, de 1934, Sand se refere dezessete vezes à noção de bem-estar (bien-être) e vinte vezes em Vers la Médicine Sociale, de $1948 .^{2}$

A influência do pensamento de Jeremy Bentham transparece na seguinte afirmação de Sand acerca da relação entre pobreza, bem-estar e saúde com base na noção de capital social:

1. Bentham foi criticado por Marx (1968, p. 708) justamente devido a esse tipo de interpretação histórica dos fenômenos sociais: "Com a mais ingênua ingenuidade, ele toma o moderno burguês, especialmente o burguês inglês, como o homem normal. Tudo o que é útil para essa estranha variedade de homens normais e para seu mundo, é útil de maneira absoluta". 2. Conforme pesquisa nos livros mencionados que constam do site Google Books. 
Toda vez que permitimos que um indivíduo, uma família ou um grupo da população desça abaixo do mínimo de bem-estar, de proteção, de cultura compatível com a saúde física e mental, estamos empobrecendo nosso capital social e preparamos para nós penalizaçôes futuras, porque será necessário recuperar ou manter com grande custo aqueles que deixamos decair (Sand, 1934).

Diante de tal afirmação, pode-se concluir que a incumbência de proteção à condição de bem-estar social cabe a todos nós, cidadãos, e não, primariamente, ao Estado e suas instituiçôes. Aparentemente, o que as lideranças da medicina social de 1946 consideravam como prioridade era a implantação de um conjunto de açôes de proteção social da população pobre, de acordo com o espírito benemérito das poor laws, que estimularam, no século XIX, a realização de mudanças focalizadas nas condiçôes de vida da pobreza. Como se sabe, o próprio Bentham chegou a coordenar essas ações, quando foi nomeado comissário-geral dos Pobres do Reino Unido.

$\mathrm{Na}$ reuniáo preparatória dos estatutos da OMS, realizada em Paris, sob a coordenaçáo de René Sand, foi dada a seguinte redação: "saúde não é somente a ausência de enfermidade ou doença, mas também um estado de aptidão física e de bem-estar mental e social" (WHO, 1946a). Dessa versão preliminar, cabe destacar o uso da expressão aptidão física, peculiar à linguagem médica, em vez de bem-estar físico.

Comparando as duas redaçóes, conclui-se que a noção de "completo bem-estar", que veio a ser o aspecto mais polêmico da definiçâo final acordada em Nova Iorque, resultou de uma modificação introduzida na reuniáo de Nova Iorque, embora o entendimento da saúde com base na noção de bem-estar estivesse presente desde as discussóes iniciais em Paris. Não obstante, René Sand não foi o responsável por essa definição. Como se sabe disso? Pelo fato de que não pôde participar da reunião de Nova Iorque devido, ironicamente, a um problema de saúde (WHO, 1946b).

Entendemos que a concepção de bem-estar, segundo a medicina social dessa época, tinha um caráter essencialmente liberal. A expectativa do alcance da saúde relacionava-se, mais que nada, com as novas funçôes de proteção específica da saúde que os médicos tinham a exercer pela prática da medicina social. Diante dos problemas sanitários que afetavam os pobres no pós-guerra, os médicos esperavam encontrar uma solução no âmbito da esfera técnico-social da medicina liberal como prática médica autônoma. Portanto, ainda não tinham a possibilidade de pôr em prática um conjunto heterogêneo de políticas públicas desenvolvimentistas, conduzidas diretamente pelo Estado na condição de uma reforma sanitária como seria defendido por Gunnar Myrdal por ocasiāo da V Conferência da OMS, em 1952. 


\section{AS CRÍTICAS À DEFINIÇÃO DE SAÚDE DA OMS}

A definição da OMS acerca da saúde como completo bem-estar tornou-se famosa, mas, ao mesmo tempo, alvo de inúmeras críticas, que afirmam, por exemplo, que a saúde não é um estado, mas uma capacidade; ou, ainda, que a concepçáo de saúde como uma condição de completo bem-estar baseia-se numa visão idealizada da condição humana, que deve ser considerada contingente, em sentido filosófico, ou falível, em sentido teológico.

Como exemplo representativo do tipo de crítica estritamente filosófico, convém citar o que diz o renomado teólogo brasileiro Leonardo Boff:

essa compreensão não é realista, pois parte de uma suposição falsa, de que é possível uma existência sem dor e sem morte (...). Acresce ainda que a saúde não é um estado, mas um processo permanente de busca de equilíbrio dinâmico de todos os fatores que compóem a vida humana (Boff, 1999, p. 44).

Outra crítica, mas de cunho sociológico, foi empreendida em artigo de autoria de nada menos que quatorze pesquisadores de saúde pública em âmbito internacional. Os autores consideraram que o objetivo idealizado da "saúde como completo bem-estar" contribui para a medicalização da sociedade, mediante o uso excessivo e potencialmente nocivo de recursos terapêuticos:

a exigência de saúde completa deixaria doente a maioria de nós. Tal noção apoia, portanto, as tendências de expansão da tecnologia médica e das indústrias farmacêuticas, em conluio com as organizaçôes profissionais, no sentido de redefinir as doenças, ampliando o escopo da assistência no sistema de saúde (Huber et al., 2011, p. 1).

Entendemos que essa denúncia carece de fundamento histórico, porque pressupóe que a indução generalizada ao consumo de medicamentos já fosse uma estratégia adotada pela indústria farmacêutica dos anos 1940, algo que somente ocorreu décadas depois, como um fenômeno conectado à globalização econômico-social.

Alguns críticos cometem claros equívocos epistemológicos, como é o caso de Daniel Callahan, que expóe uma crítica notavelmente contraditória, uma vez que enfatiza as condiçóes particulares ou individuais de cada um como relevantes para a compreensão de um conceito de caráter tão universal quanto o da saúde: 
sugiro que resolvamos o seguinte: "a saúde é um estado de bem-estar físico". Esse estado não precisa ser "completo", mas deve ser pelo menos adequado, isto é, sem prejuízo significativo da função. Também não precisa abranger o bem-estar "mental"; alguém pode ser saudável, mas ansioso, bem deprimido. E certamente não deve abranger "bem-estar social", exceto na medida em que esse bem-estar seja prejudicado pela presença de enfermidades físicas graves e em larga escala (Callahan, 1973, p. 80).

Todas essas críticas costumam considerar a definição da OMS per se, ou seja, em separado do seu caráter político-institucional. No entanto, é preciso lembrar que a OMS, ainda em seu nascedouro, buscava estabelecer certos objetivos estratégicos de cooperação internacional com vistas à recuperação econômica e social dos países na conjuntura do pós-guerra. Assim, entendemos que a definição da $\mathrm{OMS}$ não pode ser lida como tendo resultado de um juízo de caráter meramente autoral, mas deve ser analisada como uma consigna político-institucional, envolvendo objetivos explícitos e implícitos peculiares à missão da OMS na conjuntura histórica de seu nascedouro. No que segue, pretendemos justamente destacar o caráter institucional da definição da OMS.

\section{UMA HIPÉRBOLE DESENVOLVIMENTISTA PRECOCE}

O que não foi dito por René Sand e seus colegas da medicina social, porque inexistia tal concepção em 1946, é que o completo bem-estar social deveria advir, de algum modo, de um processo nacional de desenvolvimento. Somente em 1952 iria surgir a ampla e profunda interpretação de Gunnar Myrdal acerca da reforma sanitária, como condutora de um bem definido como política econômico-social, capaz de reduzir as desigualdades sociais no campo da saúde.

Em nosso entender, o conceito de saúde como completo bem-estar caracteriza-se por embutir uma promessa político-institucional e, nesse sentido, constitui uma hipérbole desenvolvimentista precoce. Como toda hipérbole, está marcada por um estilo de exagero retórico. Contudo, graças a essa hipérbole, foi possível reconhecer a saúde como um objetivo relevante dos processos nacionais de desenvolvimento e como um direito que deveria assistir a todos. Pode-se dizer que a noção de saúde como completo bem-estar desempenhou a mesma função de outros conceitos bastante abrangentes e carregados de sentido axiológico, que emergiram nas décadas seguintes, a exemplo de desenvolvimento sustentável e direitos humanos. Essa hipérbole fez sentido especial, visto que pôde dar ânimo ao ativismo sanitário em múltiplos países do planeta e ao engajamento da OMS nas iniciativas pela melhoria da saúde global. 
Quanto ao caráter precoce dessa consigna, entendemos que decorre do fato de ter surgido no campo das políticas de saúde antes mesmo de haver, por parte da ciência econômica, uma adequada compreensão das relaçóes entre pobreza, saúde e desenvolvimento. Como notado, a compreensão teoricamente bem embasada da relação entre saúde e desenvolvimento somente surgiria na década de 1950, mais precisamente, em 1952, por conta da exposição de importância histórica de Gunnar Myrdal, por ocasiāo da VI Conferência Internacional de Saúde da OMS (Myrdal, 1952). Nesta oportunidade, o economista sueco, então presidente do Conselho Econômico e Social da ONU, defendeu uma perspectiva desenvolvimentista voltada para a diminuiçâo das desigualdades sociais e a aceleração da produtividade da economia mediante a melhoria progressiva do desempenho de certas instituiçôes públicas e privadas.

As ideias de Myrdal a respeito da relação entre saúde e desenvolvimento foram em grande parte resultantes de seu estudo nos Estados Unidos acerca das condiçóes de desigualdade socioeconômica entre a população branca e a negra. Explicitamente, ele indicou que o bem-estar da saúde depende não apenas das açôes e políticas postas em prática nesse campo específico, mas também, de modo essencial, da amplitude e do alcance das políticas de natureza econômico-social no longo prazo, que possam contribuir para a diminuição das desigualdades sociais.

Com base na perspectiva analítica aberta por Myrdal, algumas lideranças de médicos sanitaristas brasileiros, com destaque para Josué de Castro e Mário Magalhães, passaram a analisar as condições de saúde de uma população como estreitamente dependentes das políticas de desenvolvimento e da concomitante redução das desigualdades sociais em cada país. Isto quer dizer que, se é bem verdade que as políticas específicas de saúde conduzem a resultados importantes por si mesmas, poderiam, contudo, exibir alcance social bem mais efetivo se inseridas no âmbito de estratégias desenvolvimentistas.

Os estatutos da OMS de 1946 inovaram o pensamento acerca da relação entre saúde e sociedade justamente devido à inclusão da noção de bem-estar social. Os bem-estares físico e mental já constituíam dimensôes levadas em consideração por parte dos médicos e das instituiçôes públicas de saúde na Europa e, como evidenciado, pelos próceres da chamada medicina social, liderados pelo médico belga René Sand. Contudo, a noção de bem-estar social - entendida muito além da ideia restrita do bem-estar individual - representou uma inovação, sobretudo quando se considera sua introdução numa conjuntura de pós-guerra, marcada pela desorganizaçáo da vida em sociedade e das próprias políticas públicas.

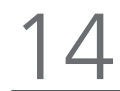




\section{MYRDAL: 0 BEM-ESTAR, OS ASPECTOS ECONÔMICOS DA SAÚDE E A IDEIA DE REFORMA SANITÁRIA}

O pensamento de Gunnar Myrdal a respeito da relação entre saúde e bem-estar da população foi exposto detalhadamente no artigo Os Aspectos Econômicos da Saúde, publicado em francês ainda em 1952. Fiel à história, Myrdal destaca, em primeiro lugar, o fato de que os estudos econômicos no campo da saúde foram realizados pioneiramente não por economistas, mas por médicos de medicina social e de saúde pública que estavam em contato com esses problemas no exercício de sua prática profissional e que, aos poucos, foram chamando a atenção dos profissionais do campo da economia e da ciência social.

Para Myrdal, a atuação isolada desses profissionais do campo da saúde teve pouco impacto sobre as condiçôes de vida dessas populaçóes. Em sua opinião, a questão básica estava em como maximizar os efeitos desse tipo de esforço coletivo por parte dos profissionais do campo sanitário. A recomendação de Myrdal dava-se no sentido da adoção de uma política de saúde que estivesse o mais intimamente possível integrada a um conjunto de reformas econômico-sociais:

para obter o máximo de efeitos benéficos em relação ao bem-estar da população, todo esforço de melhoria permanente dos níveis de saúde da população deverá estar integrado a uma política de amplas reformas econômicas e sociais. E esta política deverá estar fundada em estudos da interdependência dos vários elementos do nível de vida no caso do país considerado e no exame das possibilidades que ofereçam modificar esses elementos no sentido de uma melhoria tal que as mudanças ocorridas se apoiem mutuamente na maior extensão possível (Myrdal, 1952, p. 791).

Aqui se faz presente a noção de causalidade socioeconômica ampla e circular que constitui uma marca do desenvolvimentismo de Myrdal. Nesse particular, pode-se afirmar que os pioneiros da medicina social e da saúde pública contavam com métodos adequados de coleta de dados demográficos e sociais, contudo não dispunham ainda de uma compreensão ampla e coerente da relação entre problemas sociais e condições de saúde. Sendo assim, não anteviam a possibilidade de uma solução integradora entre políticas nacionais de desenvolvimento e políticas de saúde, tal como indicado nesse texto de Myrdal.

Myrdal trata repetidas vezes dessa proposta de reforma sanitária, que deveria abranger muito mais que a melhoria de desempenho e de cobertura do sistema de saúde, pois tinha em vista mudanças econômicas fundamentais que conduzissem ao aumento do bem-estar do conjunto da população: "as reformas sanitárias compreendem sempre um benefício adicional, impossível de ser contabilizado, o qual, numa sociedade em que os sofrimentos humanos foram atenuados, expressa-se pelo aumento do bem-estar" (Myrdal, 1952, p. 800). 
No Brasil, um tipo muito semelhante de abordagem da relação entre políticas de saúde e políticas de desenvolvimento consta do relatório final da VIII Conferência Nacional de Saúde de 1986, nos seguintes termos:

Em seu sentido mais abrangente, a saúde é a resultante das condições de alimentação, habitação, educação, renda, meio-ambiente, trabalho, transporte, emprego, lazer, liberdade, acesso e posse da terra e acesso a serviços de saúde. É assim, antes de tudo, o resultado das formas de organização social da produção, as quais podem gerar grandes desigualdades nos níveis de vida (Brasil, 1986).

De acordo com o espírito desse relatório, o conjunto ideal de condiçóes de bem-estar deveria ser garantido pelo desenvolvimento econômico-social, mas poderia também ser alcançado por meio de prioridades estabelecidas pelos governos em relação às políticas de distribuição de renda, combinadas com o maior acesso pela população a certos bens e serviços essenciais de saúde. A proposta de uma reforma sanitária no Brasil foi adiante, mas acabou por adquirir um objetivo mais restrito, que se refere apenas à radical descentralização e unificação dos serviços públicos de saúde pelo Sistema Único de Saúde (SUS), e deixou de lado suas conexôes com a questáo do desenvolvimento econômico-social, no sentido dado por Myrdal e pela própria VIII Conferência Nacional de Saúde, como mencionado anteriormente.

Como contraponto e eventual complemento ao pensamento de Myrdal, cumpre aqui salientar a relevância da reflexão que advém da conferência de Amartya Sen denominada Saúde no desenvolvimento, realizada por ocasião da LII Assembleia Mundial da Saúde, em 1999. De modo bem didático, Sen expôs suas ideias acerca do desenvolvimento como liberdade, ressaltando que uma das liberdades mais valiosas de que podemos desfrutar é aquela que decorre da possibilidade de não adoecer ou de não morrer de enfermidades evitáveis. Sen (1999, p. 621) tenciona enfatizar, desse modo, que não é preciso esperar por todas as possíveis benesses do desenvolvimento para que as condiçóes sanitárias de uma dada população nacional melhorem substancialmente, como foi comprovado pela experiência de algumas economias asiáticas em décadas recentes. Nas economias do leste e sudeste da Ásia, o aumento substantivo das oportunidades sociais (educacionais, sanitárias, entre outras) facilitou o alcance do alto desenvolvimento econômico, com aumento do emprego e, ao mesmo tempo, criou circunstâncias favoráveis à redução das taxas de mortalidade e à expansão da expectativa de vida. 


\section{MEDICINA, ECONOMIA E DESENVOLVIMENTO NO BRASIL}

Ainda na década de 1950, dois médicos formados de acordo com a perspectiva analítica de Myrdal foram reconhecidos e louvados pelos economistas justamente porque tiveram o tirocínio de agregar uma visão desenvolvimentista à linha clássica de estudos demográficos e epidemiológicos: Mário Magalhães da Silveira e Josué de Castro, ambos originários da região Nordeste. Mas, de modo geral, as ideias de Myrdal continuaram ignoradas pelos médicos com funçôes acadêmicas. Seu conceito peculiar de reforma sanitária foi relegado ao esquecimento e não ressurgiu nos ensaios teóricos acerca dos objetivos do movimento que levou à criação do SUS pela Constituição Federal de 1988 (CF/1988). Essa omissão não representou um fato isolado, visto que esse movimento não conseguiu construir uma linha interpretativa consensual acerca da questáo desenvolvimento e ateve-se basicamente aos objetivos de mudança institucional do sistema nacional de saúde e ao acesso universal e gratuito pela população.

Como os médicos tomaram essa ideia? A nosso ver, eles simplesmente não a tomaram, devido a um obstáculo epistemológico que impedia o entendimento do alcance da ideia de reforma sanitária no sentido dado por Myrdal. Os médicos sanitaristas tratavam da questão do desenvolvimento de um modo indireto, ou seja, mensurando os efeitos negativos das más condiçóes de saúde sobre os indicadores demográficos e epidemiológicos. Isso incluía, por exemplo, a distribuição da população em áreas férteis e em áreas propensas à seca, as sub-regiôes com maior prevalência de desnutrição e mortalidade infantil e as áreas de menor expectativa geral de vida.

Assim, os médicos só chegavam a tratar da questão do desenvolvimento mediante a análise de indicadores demográficos e epidemiológicos: a distribuição da população em áreas férteis e em áreas propensas à seca, a prevalência da desnutrição, a dimensão da mortalidade infantil, a expectativa média de vida da população e assim por diante. Isso tudo tinha a ver com o "valor econômico da saúde", conforme denominado em importante trabalho escrito em inglês (Ribeiro, Ferreira e Braga, 1998) e apresentado na mesma reuniáo internacional da OMS de 1952 em que Myrdal expôs suas teses sobre a relação entre saúde e desenvolvimento.

Esse ensaio trouxe uma ampla análise acerca dos indicadores epidemiológicos e demográficos que têm potencial impacto sobre a economia nacional. A introdução esclarece que um dos objetivos do estudo consiste em explicar o valor da saúde do ponto de vista das despesas e perdas causadas por doenças e outras deficiências físicas que, em todas as faixas 
etárias, reduzem ou dificultam a produtividade normal do homem saudável em um período específico de vida. Segundo os autores, tais despesas e perdas, associadas às enfermidades e às incapacidades, influenciam, de modo direto, na economia privada, individualmente e em cada grupo familiar, e na economia geral e do Estado; e, indiretamente, reduzem as taxas de produtividade individuais e das diversas faixas etárias da população da região em estudo. No fim do ensaio, os autores enfatizam que o conceito de bem-estar da OMS ratifica a garantia de que o investimento em saúde tem retornos econômicos garantidos:

o reconhecimento dos direitos do homem de gozar de um estado de saúde como o definido pela OMS não deve sofrer nenhuma restrição e já obteve aprovação por escrito em acordos internacionais e nas constituiçóes de muitos países. Este estudo enfatizou o binômio produção/bem-estar e permitiu abordar o problema da saúde a partir de um ponto vista material e concreto. No planejamento, organização hierárquica e estrutura dos serviços de saúde, os poderes governamentais deveriam encarar esse problema não do ponto de vista de uma mera alocação de recursos, mas como um investimento de capital em setor que é seguro e lucrativo (Ribeiro, Ferreira e Braga, 1998, p. 240).

Esse tipo de detalhamento teórico e empírico acerca da situação e das tendências das condiçóes de saúde foi realizado por médicos sanitaristas de muitos países, a fim de justificar intervençóes públicas que pudessem contribuir para a melhoria das condições sanitárias da população. $\mathrm{Na}$ interpretação dos médicos sanitaristas brasileiros presentes à V Conferência da OMS, esse era o tipo de análise que lhes competia fazer para convencer as autoridades nacionais e internacionais acerca da relevância econômica de medidas de controle sanitário das doenças transmissíveis.

No Brasil, quem mais divulgou as ideias de Myrdal acerca de saúde e desenvolvimento foi o médico sanitarista Mário Magalhães da Silveira. Figura dotada de notável liderança intelectual, Mário foi funcionário do Ministério da Saúde (MS) no Rio de Janeiro e desempenhou relevante papel na assessoria a Celso Furtado ao longo de todo o período em que este economista presidiu a Superintendência do Desenvolvimento do Nordeste (Sudene). ${ }^{3}$ Ao se referir ao conceito de saúde da OMS, Mário Magalhães da Silveira enfatizava:

3. Na introdução de sua obra autobiográfica, Furtado (2014) escreve: "Um companheiro já falecido, Mário Magalhães da Silveira, de alguma forma simboliza o espírito de toda uma equipe que cresceu com o correr dos anos sem nada perder de sua coesão. Reunia ele dedicação sem falha à coisa pública e o desprendimento pessoal de um anacoreta. Possuía excepcional acuidade para lhe captar o caráter das pessoas, como se dispusesse de uma lanterna mágica que permitia ler no rosto o espírito de um interlocutor. Não Ihe escapavam, nos textos que lia, as falácias mais astuciosas nem os sofismas mais sutis. Sua valiosa contribuição no campo da medicina sanitária e da demografia dissolveu-se no anonimato. Mas a exigência que tinha consigo mesmo e sua generosidade estabeleceram a pauta de comportamento de toda a equipe que construiu e defendeu a Sudene na dura procela que nos coube enfrentar." 
quem tem dinheiro, goza de saúde. Pelo menos porque pode comprá-la. Quem não tem dinheiro, dificilmente pode comprar saúde. Naturalmente que os governos podem modificar o estado sanitário de regiôes, de países etc., saneando, estabelecendo certas condiçôes que evitem certos tipos de doenças. Porém os governos não podem dar saúde, porque a saúde mesmo, na definição da Organização Mundial da Saúde, que não é nenhuma organização revolucionária, é a seguinte: saúde é um completo estado de bem-estar físico, psíquico e social. De maneira que não há médico que possa dar isso a ninguém. Só as condiçôes sociais, só a elevação das pessoas na escala social é que pode permitir um bem-estar desses (Silveira, 2005, p. 164).

A partir do que diz nessa última frase, conclui-se que Mário Magalhães da Silveira tinha uma noção clara acerca do caráter desenvolvimentista da definição da OMS e, por isso, afirmava que "só a elevação das pessoas na escala social é que pode permitir um bem-estar desses" (Silveira, 2005, p. 164). Essa perspectiva econômica de cunho desenvolvimentista é claramente contrastante com a que aparece no documento The Economic Value of Health (Ribeiro, Ferreira e Braga, 1998).

O pensamento de Mário Magalhães da Silveira teria se perdido para as geraçóes posteriores, se não fosse pela perseverança de um de seus maiores admiradores, Eduardo Kertész, economista do Ipea, que reuniu em livro uns poucos ensaios pessoais e discursos de autoridades por ele escritos sob o sugestivo título: Política Nacional de Saúde Pública. A trindade desvelada: economia-saúde-população. Com efeito, essa "trindade" sempre esteve presente nos estudos de todos os autores médicos pioneiros que se ocuparam com a questão do desenvolvimento.

Um ponto interpretativo da relação entre saúde e desenvolvimento destacado por Mário Magalhães da Silveira, com base nos estudos de Myrdal, é que o acelerado crescimento da populaçáo brasileira, a partir da década de 1950, tinha a ver mais com o processo de desenvolvimento econômico-social do que com as medidas sanitárias postas em prática pelas autoridades nacionais para o controle das doenças transmissíveis (Silveira, 2005, p. 69). Pode-se afirmar que esse tipo de interpretação das questóes de saúde por Mário Magalhães da Silveira continua plenamente válido para entender o problema econômico-social das doenças negligenciadas, tais como a malária e a hanseníase. ${ }^{4}$

4. Em 1959, quando Celso Furtado era superintendente da Sudene, Mário foi o responsável pelos programas sanitários do órgão, priorizando o abastecimento de água e o tratamento de esgotos, antes de construir hospitais. No governo Jânio Quadros, que exigiu o retorno às instituições de origem de todos os funcionários federais, voltou a assessorar os ministros da Saúde. Mesmo depois de ter sido afastado da Sudene, continuou participando do conselho da superintendência como representante do MS (Escorel, 2015, p. 2454). 
De sua parte, o médico Josué de Castro distinguiu-se pela abordagem da questão do desenvolvimento e do bem-estar a partir dos problemas da fome e da desnutrição. Em sua afamada obra Geografia da Fome, ele afirma que a fome se caracterizou como a marca distintiva de nosso desenvolvimento desigual:

o Brasil, como país subdesenvolvido, em fase de desenvolvimento autônomo e de acelerado processo de industrialização não conseguiu ainda se libertar da fome e da subnutrição que durante séculos marcaram duramente a sua evolução social, entravando o seu progresso e o bem-estar social do seu povo (Castro, 1984, p. 289).

Fiel ao pensamento da corrente de interpretação do "valor econômico da saúde", que é mensurável pelos dados bioestatísticos, Josué de Castro concluía que a desnutrição crônica constituía o principal óbice para a integração econômica nacional devido a suas expressôes na incapacidade para o trabalho e nos baixos índices de longevidade da população (Castro, 1984, p. 290).

\section{O BEM-ESTAR DE ONTEM E DE HOJE}

O conceito de saúde como completo bem-estar, embora sujeito a variadas interpretaçóes e críticas do ponto vista estritamente filosófico, representou uma ideia-chave que, ao longo dos anos que se seguiram ao fim da Segunda Grande Guerra, ajudou a tornar mais claros os objetivos prioritários das políticas públicas internacionais de saúde em sua relação com o desenvolvimento econômico-social.

Em décadas recentes, essa concepção de saúde pôde ser, de certo modo, ultrapassada por interpretaçóes mais abrangentes, não mais focadas apenas no contexto epidemiológico das doenças transmissíveis. É o caso da ideia de saúde como liberdade, proposta de modo muito original por Amartya Sen e que tem em conta, de forma mais adequada do ponto de vista interpretativo, todo o universo da crescente prevalência das doenças crônicas não transmissíveis e de suas incapacidades (seção 2).

Entretanto, de várias maneiras, ainda hoje a ideia de bem-estar sobrevive como prioridade da saúde pública devido a se associar, por exemplo, à questão das doenças tropicais negligenciadas. Essas doenças consistem em cerca de vinte tipos e grupos de doenças transmitidas por bactérias, vírus e parasitas. Afetam populaçóes que vivem em 
condiçôes miseráveis em áreas tropicais e subtropicais, envolvendo um grupo populacional de nada menos que 1,5 bilháo de pessoas, dos quais 200 mil morrem a cada ano devido a doenças como raiva e dengue (Norris et al., 2012). Por sua vez, a falta de acesso oportuno ao tratamento dessas doenças tropicais negligenciadas deixa centenas de milhôes de pessoas severamente incapacitadas, desfiguradas ou debilitadas. A esse respeito, em 2004, o relatório final de um encontro internacional, elaborado sob a coordenação do médico e pesquisador da Fiocruz Carlos Morel, faz a seguinte avaliaçáo crítica, que, de modo enfático, retoma a noção de bem-estar:

Evidências recentes mostram que a melhoria da saúde é mais do que uma consequência do desenvolvimento. É um insumo central no desenvolvimento econômico e social e na redução da pobreza. Boa saúde, desenvolvimento econômico e bem-estar econômico individual são intimamente interdependentes (Morel et al., 2005, p. 2).

Observa-se aqui, mais uma vez, que a invocação da noção de bem-estar é quase inevitável quando se discute o problema das chamadas doenças de massa, particularmente no caso das doenças negligenciadas, peculiares à extrema pobreza.

Pode-se afirmar que, para esse amplíssimo contingente populacional, o desenvolvimento fundado no completo bem-estar físico, psíquico e social, tal como prometido pela OMS em 1946, de fato ainda náo chegou, ou chegou de modo assaz incompleto, ou seja, precariamente. Invocar a noção de bem-estar continua a ser uma opção plenamente válida no plano dos objetivos e resultados das políticas internacionais de saúde. Mais que isso, a ideia de saúde como bem-estar continua a exibir um forte apelo emocional e político, que dificilmente seria alcançado mediante concepçóes contemporâneas, como as que serão discutidas a seguir.

\section{OUTRAS CONCEPÇÕES DA SAÚDE HUMANA PARA ALÉM DO BEM-ESTAR}

Esta seção apresenta concepçóes da saúde que se apresentam como um contraponto à noção de bem-estar segundo a tradição utilitarista, exposta anteriormente, e discute as limitaçôes dessa tradição, bem como duas concepçôes distintas acerca da liberdade humana. 


\subsection{0 bem-estar bem segundo a fenomenologia de Heidegger}

Analisada de acordo com os fundamentos da filosofia fenomenológica de Martin Heidegger, a compreensão da saúde como completo bem-estar deve ser entendida atrelada à dicotomia cartesiana entre sujeito e objeto, que constitui a referência fundamental do pensamento metafísico moderno desde Descartes. Quem está bem de saúde é o sujeito na sua relação consigo mesmo e na relação com os objetos e os demais sujeitos que o cercam, os quais, juntos, compóem a sociedade. Disto resulta que a saúde é entendida desde logo como envolvendo algum sentimento de prazer ou gratificação por parte do sujeito em relação aos objetos naturais e sociais e às possíveis escolhas de cada sujeito, tal como claramente explicitado pioneiramente pela doutrina utilitarista de Bentham.

Essa noção de bem-estar está em nítido contraste com a noção fenomenológica do estar bem exposta por Heidegger numa série de seminários ministrados entre 1959 e 1969, na cidade suíça de Zollikon. O filósofo alemão afirmou para uma audiência seleta de psiquiatras e psicólogos que, "na condição de enfermidade, o estar bem, próprio da saúde, não está simplesmente ausente, mas, sim, perturbado" (Heidegger, 2006, p. 58; 2001, p. 73). Para essa compreensão, a enfermidade não constitui uma mera falta ou privação da saúde, mas um distúrbio do modo de ser saudável humano, que está marcado essencialmente pela liberdade de ser, em relação a si mesmo, aos outros e ao mundo como um todo (Nogueira, 2011).

O estar bem peculiar à saúde, segundo Heidegger, não se manifesta como uma sensação de prazer gratificante, mas como um sentir-se livre no mundo, em contraste com a condição de enfermidade, que desperta uma sensação de tolhimento, ou seja, de obstrução dessa forma essencial de liberdade. Para esclarecer essa importante questão da hermenêutica da relaçáo entre saúde e enfermidade, cumpre citar por inteiro o que Heidegger disse a esse respeito para sua audiência de médicos e psicólogos:

o ser saudável (gesundsein), o estar bem (wohlbefinden), o encontrar-se bem, não está simplesmente ausente, mas está perturbado (gestört). A enfermidade não é a pura negação da condiçãa psicossomática. A enfermidade é um fenômeno de privação (privation). Toda privação implica na pertinência essencial (zugehörigkeit) de alguma coisa a uma outra que lhe faz falta e que lhe foi subtraída. Isto parece ser trivial, mas é extremamente importante, porque a profissão dos senhores move-se nesse contexto. Na medida em que os senhores lidam com a enfermidade, lidam, na verdade, com a saúde (gesundheit) no sentido de que a saúde está em falta e precisa ser ganha (Heidegger, 2006, p. 58-59). 
Heidegger (2006) explica que o tipo de privação que caracteriza o enfermo pode ser assim resumido de modo didático: "é uma perturbação de seu sentir-se em casa no mundo, vivido como um demorar de um mal que desorganiza e ameaça a existência humana e sua liberdade de ser no mundo".

Toda enfermidade implica uma perda das possiblidades de ser livre no mundo. Isto quer dizer que a enfermidade como tal não é caracterizada simplesmente pela ausência de saúde, ou seja, como um fenômeno de privação, mas, sim, pelo distúrbio da relação com o mundo: "o estar bem, o encontrar-se bem, não está simplesmente ausente, mas está perturbado” (Heidegger, 2006). Convém chamar atenção, nesse contexto, para a riqueza da palavra wohlbefinden em alemáo, que tanto pode ser traduzida por bem-estar quanto por estar bem ou, ainda, encontrar-se bem.

A abertura para o ser e para si mesmo que é a peculiar Dasein (ser-aî), como acentua Heidegger repetidamente, não é só um trunfo, mas um grande perigo, na medida em que abrange a possibilidade de o Dasein se perder na condiçáo privativa da doença, que é sempre restritiva de sua liberdade. O entendimento de Heidegger acerca dessa vulnerabilidade humana essencial diante de sua liberdade pode ser resumido da seguinte maneira: "o Dasein está diante de possibilidades que ele não antevê; é sujeito a mudanças que não conhece; move-se constantemente numa condição sobre a qual não tem domínio" (Heidegger, 2006).

Heidegger acentua no Seminário de Zollikon que, por isso mesmo, o homem encontra-se sempre em perigo de se perder na enfermidade e náo dar conta de si mesmo. Devido a sua própria liberdade, o ser humano é essencialmente necessitado de ajuda.

O homem é essencialmente necessitado de ajuda porque se encontra sempre no perigo de se perder (verlieren) e a ponto de não dar conta de si mesmo. Esse perigo (gefahr) relaciona-se com a liberdade do homem. A totalidade da questáo do poder-ex-istir perturbado (krankseinkönnen) relaciona-se com a imperfeição de sua essência. Cada enfermidade é uma perda (verlust) de liberdade, uma limitação da possibilidade de viver (Heidegger, 2006, p. 199-202; 2001, p. 178-180).

Desse modo, Heidegger entende que há uma falibilidade essencial da liberdade do ser-humano que pode, sem motivos aparentes, entregar-nos à condiçáo de enfermidade. É justamente esse ser-livre essencial que nos faz correr o perigo de um mergulho perturbador e duradouro no modo de ser-enfermo. Nos termos de sua análise 
fenomenológica, a enfermidade é uma perda perturbadora da relação essencialmente livre mantida por cada um com as pessoas e com as coisas. Esse é um aspecto relevante ignorado por completo pela interpretação de saúde como bem-estar.

Segundo Heidegger, na medida em que a liberdade não se fundamenta em nada e, por assim dizer, ergue-se sobre o abismo dessa falta, o ser humano é sempre suscetível de se perder, de não dar conta de si mesmo, ao tentar haver-se com as exigências que o mundo cotidiano impóe às possibilidades de sua liberdade. A projeção temporal-espacial do ser-humano como Dasein torna-o pouco adaptável a seu meio social, ao contrário do que ocorre com os animais, que são incapazes, por exemplo, de criar expectativas acerca de seu futuro. Por se limitarem a dar respostas a estímulos imediatos, os animais, conforme Heidegger, são mais bem adaptados a seu ambiente do que o ser humano.

Ao carregar cotidianamente o fardo da sua liberdade, o ser humano é essencialmente necessitado de ajuda, porque está sempre a ponto de se perder. Segundo Heidegger, há no ser humano uma falta de firmeza que decorre justamente de sua abismal liberdade. É daí que advém o perigo de ele não conseguir lidar com as demandas que o mundo lhe dirige. De outra parte, ele considera que a enfermidade se dá como uma limitaçấo e um distúrbio das possibilidades de viver livremente na cotidianidade, visto que conduz a um fechamento existencial duradouro e perturbado.

Essas breves referências aos fundamentos do pensamento de Heidegger acerca da saúde como estar bem serve de contraponto filosófico à concepçáo da saúde como bem-estar, embora, à primeira leitura, possa parecer que haja entre as duas expressóes apenas uma diferença de ordem dos termos.

\subsection{0 conceito de capacidades humanas de Amartya Sen e o novo contexto epidemiológico de prevalência das doenças crônicas não transmissíveis}

Amartya Sen e Heidegger têm pelo menos um ponto doutrinário em comum: pensar a saúde do ser humano como liberdade na relação com o mundo. Pode-se afirmar que Heidegger detém-se nos aspectos ontológicos ou universais da enfermidade, como um comportamento peculiar ao ser humano, enquanto Sen detém-se nos aspectos filosóficos concretos ou ônticos das privaçôes, que são peculiares às pessoas e aos grupos sociais e aos seus estilos de vida particulares. 
Em maio de 1999, Amartya Sen fez uma exposição na OMS sobre saúde no desenvolvimento que é comparável, em termos de relevância política e acadêmica, à conferência de Gunnar Myrdal em 1952. O contraste de foco analítico entre essas duas exposiçóes pode ser compreendido adequadamente quando se considera o fato de ter ocorrido, desde a década de 1950, o referido processo de transição epidemiológica (Omram, 2005), que fez com que as doenças crônicas não transmissíveis, tais como as cardiovasculares, o câncer e o diabetes, ganhassem relevância na estrutura de mortalidade de todos os países em desenvolvimento, como também na cotidianidade da vida de seus cidadãos. Essas doenças caracterizam-se, entre outros aspectos, pelo fato de darem origem a diversas formas de incapacidade, que tolhem a liberdade humana de modo mais ou menos duradouro.

Myrdal falava da relevância do desenvolvimento para a saúde tendo em vista, mais que nada, o impacto das doenças transmissíveis sobre o bem-estar da população pobre. Em contraposição, o assunto prioritário de Sen, nesse campo, é a relação entre a enfermidade incapacitante e as liberdades humanas, algo que afeta a todos os grupos sociais. As incapacidades físicas, mentais e sociais decorrentes das doenças crônicas não transmissíveis diminuem drasticamente a liberdade das pessoas por elas afetadas independentemente de gozarem ou não de uma condição de bem-estar social, embora, naturalmente, as pessoas que dispóem de maiores recursos materiais possam mais facilmente encontrar os meios paliativos da condição restritiva de sua liberdade.

O conceito de capacidades humanas de Sen é equiparável à noção de liberdade pessoal como uma potencialidade. Resulta disso que toda forma de privação dessas capacidades, que são muito frequentes na vigência de certas doenças crônicas não transmissíves e de suas sequelas, deve ser vista como uma perda da amplitude de suas escolhas diante do estilo de vida que almejam, caracterizando uma restrição da liberdade pessoal. Nessa situação, prevalecem variados tipos de desabilidade física ou mental que podem perdurar por toda a vida.

Cada um de nós dispóe de um conjunto de capacidades, do qual decorre um vetor de funcionamentos na vida cotidiana, envolvendo, por exemplo, atividades de trabalho, educação, esporte e lazer. As enfermidades crônicas não transmissíveis e suas sequelas podem obstruir esses funcionamentos de modo temporário ou definitivo e, com isso, obstruir a possibilidade de construir modos alternativos de vida para o futuro. 
O conceito de capacidade humana, segundo Sen, pode ser definido como a liberdade de alcançar combinações alternativas de funcionamentos valorizados socialmente, de modo a compor uma variedade de estilos de vida potencialmente alcançáveis por cada pessoa em seu cotidiano. Sen considera que fatores sociais e econômicos tais como educação, cuidados básicos de saúde e emprego seguro são importantes não tanto por si mesmos quanto pela oportunidade que podem oferecer às pessoas de enfrentar o mundo com coragem e liberdade. As capacidades representam "liberdades substantivas" para escolher a vida que a pessoa tem razão em valorizar. Com base nessa concepção de justiça social, Sen combina livremente traços do libertarianismo e do utilitarismo.

A pobreza, segundo Sen, constitui, em si, uma privação de tais capacidades básicas e não apenas a expressão de uma condição socioeconômica de carência de renda. Explicitamente, essa forma de privação não somente dificulta a realização de renda, mas, igualmente, dificulta a conversão da renda em funcionamentos socialmente adequados. A grande importância de tal concepção está no fato de apontar para a necessidade de mudar o alvo do desenvolvimento, passando dos meios (distribuição de recursos) para os fins (alcance de realizaçôes ou funcionamentos) que as pessoas valorizam.

Segundo essa ótica das capacidades humanas, existe uma relatividade da riqueza em relação à pobreza. Alguém que é rico, mas que padece de enfermidade grave e intratável, tem uma privação que, em sentido significativo, pode ser maior que a de um trabalhador pobre desempregado, mas sadio, que conta com auxílio do seguro-desemprego.

Essa ênfase na necessidade de uma abordagem multidimensional do desenvolvimento constitui-se em peça fundamental do pensamento de Sen, que propóe: i) combinar a ampliaçáo e a diversificação do mercado com o aumento da oferta de oportunidades sociais; ii) assegurar diferentes vias distributivas de acesso a bens públicos por parte da população carente; e iii) oferecer subsídios e transferências de renda em complemento ao aprimoramento das capacidades básicas, especialmente nas áreas de saúde, educação e segurança social. Nesse sentido, Pinheiro (2012, p. 9) enfatiza adequadamente que a interpretação de Sen "contrasta com as visôes tradicionais, que restringem o desenvolvimento ao crescimento do produto nacional, ao crescimento da renda pessoal, à industrializaçấo, ao avanço tecnológico ou à modernização social”. 
As "liberdades instrumentais" a serem consideradas no processo social de desenvolvimento estáo relacionadas às liberdades políticas, às facilidades econômicas (no acesso ao mercado), às oportunidades sociais (em educação, saúde etc.), às garantias de transparência interpessoal (confiança na segurança do convívio público) e à segurança social que advém de benefícios de proteção ao trabalho e de previdência social. Daqui surge um ponto de vista filosófico e econômico que é radicalmente contraposto à tendência prevalente a avaliar o sucesso do desenvolvimento com base unicamente no crescimento do produto interno bruto (PIB).

A visão do desenvolvimento como liberdade contempla a perspectiva liberal de expansão das liberdades que temos razão em valorizar porque torna nossas vidas mais ricas e nos faz pessoas socialmente mais plenas. Contempla, igualmente, a visão crítica do social, para além das questôes da pobreza e do desenvolvimento, visto que mesmo os países ricos muitas vezes têm pessoas em situaçóes de profunda desvantagem devido à falta de oportunidades básicas relacionadas com saúde, educação, trabalho e segurança social. Sen agrega um importante dado histórico sobre democracia e privaçôes sociais: em países democráticos, nunca ocorreu uma epidemia de fome. Isso acontece pelo fato de que as autoridades políticas se sentem obrigadas a ouvir a vontade popular, porque querem se reeleger, e adotam medidas preventivas em relação às causas da fome.

A discussão pública (razão pública) colabora para a expansão das capacidades básicas de todos os envolvidos, possibilita que o povo seja ouvido em seus reclamos políticos (direitos democráticos) e faz com que as "necessidades" (incluindo as econômicas) sejam mais bem conceituadas em suas variadas dimensôes e não reduzidas à questáo da renda pessoal ou familiar.

Sen usa a abordagem das capacidades como uma forma de criar consciência sobre o que é socialmente injusto - como munição para o debate público. Assim, a equidade em saúde é vista como integrante do conceito mais amplo de imparcialidade e justiça dos arranjos sociais, aí incluída a distribuição econômica, mas conferindo também a devida atenção ao papel da saúde nas liberdades humanas, com consideraçôes específicas desse campo, necessariamente integradas à avaliação da justiça social. 


\section{9 À GUISA DE CONCLUSÃO}

As três perspectivas interpretativas da relação entre saúde e sociedade apresentadas neste trabalho não foram escolhidas por serem complementares entre si e tampouco para evidenciarem a superioridade de uma em relação a outra ou, ainda, a fim de originarem uma síntese interpretativa original. A definição de saúde como completo bem-estar é a única que transcende uma abordagem estritamente autoral, por estar vinculada à história e aos objetivos prioritários de uma instituição internacional, a OMS.

Por sua vez, as interpretaçôes de saúde como o estar bem da liberdade do $D a$ sein, segundo Heidegger, e como liberdade inerente às capacidades humanas, segundo Sen, têm fundamentos filosóficos singulares na doutrina de cada um desses autores e, portanto, não são comensuráveis entre si. Uma diferença fundamental entre esses dois autores consiste no fato de que Heidegger pretende, de alguma maneira, criar um modo de pensar que supere de vez a cultura filosófica da modernidade, enquanto Sen pensa em termos de mudanças sociais que afastem os constrangimentos que limitam a liberdade de cada pessoa em optar pelo estilo de vida que lhe pareça mais adequado.

Pelo que nos foi factível de recuperar historicamente nesta resenha crítica, conclui-se que o conceito institucional de saúde como completo bem-estar demonstrou uma surpreendente capacidade de resistir ao tempo e inspirar a formulação de novas políticas internacionais de saúde, tal como acontece nos dias atuais em relação à persistente prevalência das doenças tropicais nos países do terceiro mundo. Invocar a noção de saúde como bem-estar ainda parece ser, para esses sanitaristas, a melhor maneira de justificar filosófica e politicamente a adoção de políticas desenvolvimentistas.

Assim, o fato de o conceito de saúde como completo bem-estar deitar raízes na filosofia utilitarista do século XIX não constituiu motivo suficiente para que os médicos sanitaristas buscassem alternativas conceituais, a exemplo da noção de saúde como liberdade segundo Amartya Sen. Ao economista indiano, tem sido prestadas as devidas homenagens pela OMS, mas seu pensamento ainda não logrou se projetar no cenário das reinvindicaçôes políticas desse campo. Nesse sentido, pode-se concluir que os médicos de saúde pública continuam apegados à possibilidade de investigar e mensurar o bem-estar da saúde mediante variáveis demográficas e epidemiológicas. Desse modo, continuam a cultivar a linha tradicional de investigação sobre o valor econômico da saúde, atualizada e revitalizada mediante a teoria da transição epidemiológica. 


\section{REFERÊNCIAS}

BENTHAM, J. An introduction to the principles of morals and legislation. Kitchener: Batoche Books, 2000.

BOFF, L. Saber cuidar: ética do humano - compaixão pela terra. Petrópolis, Rio de Janeiro: Vozes, 1999.

BRASIL. Ministério da Saúde. VII Conferência Nacional de Saúde - Relatório final. Brasília: MS,1986. Disponível em: <https://bit.ly/2ELX0Wl>.

CALLAHAN, D. The WHO definition of 'health'. The Hastings Center Studies, v. 1, n. 3, p. 77-87, 1973.

CASTRO, J. Geografia da fome. Rio de Janeiro: Edições Antares, 1984.

ESCOREL, S. Mário Magalhães: desenvolvimento é saúde. Ciência \& Saúde Coletiva, v. 20, n. 8, p. 2453-2460, 2015.

FURTADO, C. Obra autobiográfica. Rio de Janeiro: Companhia das Letras, 2014.

HEIDEGGER, M. Seminários de Zollikon. 2. ed. rev. Petrópolis: Vozes, 2001.

Zollikoner Seminare: protokolle, gespräche, briefe. 3. ed. Frankfurt am Main: Vittorio Klostermann, 2006.

HUBER, M. et al. How should we define health? BMJ: British Medical Journal, n. 343, 2011. MARX, K. O capital, crítica da economia política. Rio de Janeiro: Civilização Brasileira, 1968. v. 2.

MOREL, C. M. et al. Health innovation in developing countries to address diseases of the poor. Innovation Strategy Today, v. 1, n. 1, p. 1-15, 2005.

MYRDAL, G. Les aspects économiques de la santé. Revue économique, v. 3, n. 6, p. 785-804, 1952.

NOGUEIRA, R. P. Extensão fenomenológica dos conceitos de saúde e enfermidade em Heidegger. Ciência \& Saúde Coletiva, v. 16, n. 1, p. 259-266, 2011.

NORRIS, J. et al. Social and economic impact review on neglected tropical diseases. Washington, D.C.: Hudson Institute, 2012.

OMRAM, A. R. The epidemiologic transition: a theory of the epidemiology of population change. The Milbank Quarterly, v. 83, n. 4, p. 731-757, 2005.

PINHEIRO, M. M. S. As liberdades humanas como bases do desenvolvimento: uma análise conceitual da abordagem das capacidades humanas de Amartya Sen. Brasília; Rio de Janeiro: Ipea, 2012. (Texto para Discussão, n. 1794). 
RIBEIRO, P. de A.; FERREIRA, M. J.; BRAGA, E. Economic value of health. Revista Brasileira de Epidemiologia, v. 1, n. 3, 1998.

SAND, R. L'économie humaine par la médecine sociale. Paris: Rieder, 1934.

SEN, A. Health in development. Bulletin of the World Health Organization, v. 77, n. 8, 1999.

SILVEIRA, M. M. Política Nacional de Saúde Pública - A trindade desvelada: economia-saúde-população. 3. ed. Rio de Janeiro: Revan, 2005.

WHO - WORLD HEALTH ORGANIZATION. Minutes of the technical preparatory committee for the international health conference held in Paris from 18 March to 5 April 1946. Paris: United Nations, World Health Organization Interim Commission, 1946 a.

Summary report on proceedings minutes and final acts of the international health conference held in New York from 19 June to 22 July 1946. New York: United Nations, World Health Organization Interim Commission, 1946b.

\section{BIBLIOGRAFIA COMPLEMENTAR}

SEN. A. ¿Por qué la equidad en salud? Pan Am J Public Health, v. 11, n. 5/6, 2002.

The idea of justice. Cambridge: Harvard University Press, 2009.

WHO - WORLD HEALTH ORGANIZATION. First WHO report on neglected tropical diseases: working to overcome the global impact of neglected tropical diseases. Geneva: WHO, 2010. 

Ipea - Instituto de Pesquisa Econômica Aplicada

Assessoria de Imprensa e Comunicação

EDITORIAL

\section{Coordenação}

Reginaldo da Silva Domingos

Assistente de Coordenação

Rafael Augusto Ferreira Cardoso

\section{Supervisão}

Camilla de Miranda Mariath Gomes

Everson da Silva Moura

\section{Revisão}

Amanda Ramos Marques

Ana Clara Escórcio Xavier

Clícia Silveira Rodrigues

Idalina Barbara de Castro

Luiz Gustavo Campos de Araújo Souza

Olavo Mesquita de Carvalho

Regina Marta de Aguiar

Hellen Pereira de Oliveira Fonseca (estagiária)

Ingrid Verena Sampaio Cerqueira Sodré (estagiária)

\section{Editoração}

Aeromilson Trajano de Mesquita

Cristiano Ferreira de Araújo

Danilo Leite de Macedo Tavares

Herllyson da Silva Souza

Jeovah Herculano Szervinsk Junior

Leonardo Hideki Higa

\section{Capa}

Danielle de Oliveira Ayres

Flaviane Dias de Sant'ana

\section{Projeto Gráfico}

Renato Rodrigues Bueno

The manuscripts in languages other than Portuguese published herein have not been proofread.

\section{Livraria Ipea}

SBS - Quadra 1 - Bloco J - Ed. BNDES, Térreo

70076-900 - Brasília - DF

Tel.: (61) 2026-5336

Correio eletrônico: livraria@ipea.gov.br 

Composto em adobe garamond pro 12/16 (texto) Frutiger 67 bold condensed (títulos, gráficos e tabelas) Brasilia-DF 



\section{Missão do Ipea}

Aprimorar as políticas públicas essenciais ao desenvolvimento brasileiro por meio da produção e disseminação de conhecimentos e da assessoria ao Estado nas suas decisões estratégicas.

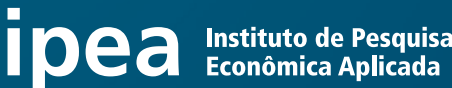 \\ MINISTÉRIO DA \\ ECONOMIA

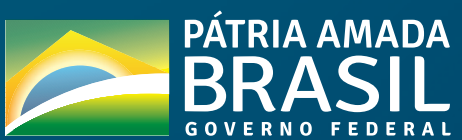

